\title{
DO WE NEED A NEW THEORY OF DRAWING? EXPLORATION ON TECHNOLOGICAL CHANGE BETWEEN PHYSICAL AN DIGITAL VISUALISATION
}

\author{
Mauricio NOVOA \\ School of Computing, Engineering and Mathematics, Western Sydney University
}

\begin{abstract}
This article proposes a framework for current use and future potential for drawing to present, represent, simulate and visualise the world within the education, industry, practice and research landscapes. Today's metamodernism allows to reimagine this paper's focus as an act of drawing, rejecting and redrawing together modernism and post-modernism to visualise solutions for complex matters of concern. Modernist technology, built on Monge's orthographic projection, initiated computer-aided design and made possible to specify matters of fact and function that lacked ornament digitally. While postmodernists deconstructed modernity with the irony of acrobatic aesthetics and technology based on a renewed approach of "art for art's sake". Fittingly, current incremental innovations are bringing about new forms of connection, informed knowledge, involvement, narratives and storytelling that can help the reinterpretation and agency of drawing for this day and age. Particularly, these developments query whether a designer's first-person observer-independent world view is enough to elicit ideation, conceptualisation and design. New product development teams are gradually becoming distributed globally and work in their own simulated virtual world environments. Their drawings structure simulations that can be tested digitally to save on material development and production, can be prototyped easily as material artefacts because new types of manufacturing, and increasingly, are becoming the end goal of design activity. Drawing principles are changing their application from the corner of two-dimensional emersion of individual ideas to the opposite of three-dimensional immersion into the design environment as embodied cognitive and enactivated experiences that express its participants' interaction with real and simulated environments.
\end{abstract}

Keywords: Design education, drawing, embodied cognition, enactivism, sketching

\section{INTRODUCTION}

Consultation with practitioners showed lack of consistency about what is drawing besides the mention of its fundamental principles. It was a case of people assuming that everybody understood the same. However, there was lack of inquiry and definition on whether that was so, and what is drawing good for now and its potential for the future. Modern standards establish a divide between freehand drawing and technical draughting that is used in architecture and engineering documentation for construction and production. Both sides insist in a notion of good drawing with different definitions and measures to validate their outcomes. The former emphasises quick and rapid generation of sketches that might later evolve into elaborated drawings as illustration. The latter is measured by specific coding, methods and rules for technical representation. Locally, technical drawing is fixed as per AS 1100 Australian Standard. Increasingly, high school students are learning technical draughting as part of threedimensional computer-aided design (3D CAD) software with their design and technology programmes while freehand drawing appears to have less support. In university, specifically in industrial design courses, students arrive with some 3D CAD understanding or skill and endure a continued push for technical drawing to prepare them for the assembly and manufacturing industry. However, there is no curricular uniformity across courses in relation to freehand drawing and what makes it a good drawing. University courses are dense and are required to deliver vast amount of content in three or four-year courses. Understandably, it was found that freehand drawing has been often unattended because either financial, skill, space and/or time constrains. Therefore, it generally falls on each lecturer to tell what 
the standards for a good drawing are. There is also a conventional view that you are either capable to draw freehand well because of innate talent from the word go, or you must dedicate yourself to hard labour to learn it which takes longer than the length that a course can cover. Concerned lecturers try to help students to grasp the basics of drawing skills for representation. It was observed some methods are to teach by copying exemplars and the use of templates and outlines (e.g. hard copies, Photoshop and Illustrator files). Students need to fill them hoping for an outcome similar to design illustration benchmarks in design illustration books. Often, lecturers and students feel a sense of achievement in a unit with exercises in a style of colouring between the lines or painting by numbers. However, it is still an open question how to unleash the potential of drawing as an ideation, conceptualisation, production and visualisation tool in an environment that is further complicated with new variables this century.

Science and social sciences note a paradox between the increasing loss of attention span and manual dexterity from Millennials (born from 1980) to Gen Z (born from 1995) and Gen Alpha (born from 2010) in contrast with their gain of digital agility as superficial users of technology [1][2]. This is a syndrome that manifest at different levels and risk creating a vicious circle in design and its education. For instance, students arrive to university increasingly with an engrained tendency to be shallow thinkers who prefer to be told what to do. This predisposition produces inertia that is not helped by youth's decrease of coordination, fine-gross motor and muscular strength. User-computer interface technology is still not fully user friendly. Devices are greatly directed to technical draughting (e.g. keyboard, mouse) and gaming (e.g. joystick). Newer technologies are trying to break that barrier. However, cost constrains make them prohibitive for general access (e.g. high-resolution pressure sensitive tablets, natural user interfaces, augmented and virtual reality). Meanwhile, research tells that freehand drawing improves cognitive and motor skills, hand-eye coordination, learning how to write, thinking analytically, creatively and critically, capacity to communicate, visualise and resolve complexity, organisational skills, connective thinking, perception and meaningful work.

\section{PROBlem Statement}

The scenario mentioned above can affect or be improved by drawing as a tool for ideation, conceptualisation, process and production. This realisation led to explore current digital and physical drawing to discover how much of its application in design education keeps pace with its evolution? And what parts might need reappraisal? It was hoped that findings would help both,

- To evaluate whether a new practice and theory of drawing is needed.

- To contribute a framework as blueprint for current use and the potential future for drawing

\section{METHODOLOGY}

The research sought to carry out work on two significant areas

- $\quad$ Epistemology (from Greek epistếmē: science, knowledge; epístamai: I know; logía: discourse): This approach had a metamodernist perspective to allow us to rethink design and its education through drawing, and to assess how design can create and carry knowledge today.

- Applied Research: This methodology sought answers practically in three areas. First was the observation of students' syntactic work to visualise, and problem solve. Second was a first-person observer-independent world view semantic and semiotic experience with traditional drawing. Third was the same activity but with recent 3D virtual environment techniques.

\section{RESULTS AND DISCUSSION}

\subsection{Epistemology}

Historical legacy has produced different views on what is a good drawing. A metamodernist perspective can help us to mediate and go beyond that heritage, modernism and postmodernism. Within that timeline, drawing has gone through syntactic, semantic and semiotic shifts because of social and technology changes. The understanding on how these changes affect the activity of drawing can also translate into knowing the design practice better since the former is essential for the latter. Drawing evidences design as it conveys simultaneously a discourse that builds on visual language principles, processes and rules (syntaxis, from Greek sun: together, tassein: arrange) to form narratives of meaning (semantics from Greek sēmantikos: significant) that are open to new types of interpretation of its current and portending marks, signs and symbols (semiotics from Greek sēmeiotikos: sign, mark). However, the 
metamodernist perspective of this conference paper is not about art history. Instead it subscribes to contemporary professionalisation of philosophy that presents the opportunity for designers to actualise their common and definitional concerns.

This paper aligns with the following thinkers. Fallan [3] who proposes to construct a design history independent from aesthetics to focus on design's main concerns of context and artefact-user interaction. Sloterdijk [4], [5, 6] who studies culture, history, language, and technology in relation to space and time. His work helps to see design as situational knowledge. Hence, design solves artefact-user interaction within contexts that work as envelopes that are contained in and connected with larger envelopes that form systems similar to Matryoshka dolls. Maturana and Varela [7], [8, 9] work on embodied cognition and enactivism for modern cognitive sciences. Cognition is shaped by the coordination of an entire organism and not only on brain function. Enactivism proposes that cognition arises through active interaction between and organism and its environment. These thinkers break away from Cartesian divisions between rationalism and empiricism. Descartes [10] described reason as pure, transcendent and universal source of disembodied knowledge coming from the self. Experimentation was denounced as unable to know reality since it cannot disassociate itself from the senses.

What is good drawing has been defined and transformed by its context through history. Revisiting the past can help us now. Typically, new technology pushed craftsmen to redefine the merits and potential of drawing. Ancient history, antiquity and the Middle Ages greatly contributed to drawing with realistic image representation, syntaxis, and technical standards. Image representation (Latin imago: a copy of, likeness to; repraesentare: to bring to mind by description) helped old societies to better preserve identity, knowledge and values based on narrative and symbols. Syntaxis set the elements and principles for two-dimensional drawing (e.g. balance, depth and composition, golden ratio, hierarchy, movement, proportion, symmetry). Methods like colouring between the lines and painting by numbers explained as much a philosophy as the technology of the day. Drawing was hard and taxing to make with a silverpoint. Thus, it was notably used to outline compositions. Illumination and manuscripts were also costly and a lengthy collective process, colour pigments were codified to represent hierarchy, wealth and occupation, and their material support was difficult to work with (treated animal skin as parchment or vellum).

The Renaissance again invited to redefine what a good drawing was. Technology facilitated the activity with the fabrication of paper and the illusion of three-dimensional perspective. Drawing became more improvisatory and did more than realistic representations since then. Importantly, it opened up to presentation (Latin praesentare: to place before) of ideas based on imagination (Latin imaginari: to picture to oneself, conceptualise, hallucinate) and Vasari [11] wrote that the Italian word disegno, translated equally as design and drawing, was the base for architecture, painting and sculpture. Different names for the word drawing help to explain those new interpretations of the art until today. These can be grouped by the implicit intention to either explore, explain, model, simulate and visualise the world. In Spanish, the words for drawing and sketch imply acts of three-dimensional modelling. Thus, drawing is dibujar (from French déboissier: wood carving) while sketch is boceto (from Italian bozzetto: small, rough and unpolished stone). In France, the word drawing is dessin (from Italian disegno: design, drawing). In English, drawing comes from old Germanic (dragen: to drag, give motion, to pull) and sketch comes from French (esquisser) and both from Italian (schizzare: to squirt, splash, spatter).

Technology facilitated a social change relating to the act of drawing because of paper, graphite and other innovations in the Renaissance. Since then, drawing became an art of emersion (Latin emerso: to emerge) from carefully prepared representations to the presentation of imagined ideas that develop in the moment. Drawing was learned with scientific aspiration and rigor to explore and analyse their subjects also in hidden spaces shared with students of medicine. Masters and apprentices' drawings showed deep individual knowledge of human muscles, anatomy, geometry, mathematics and physics. However, it was not easy or possible to share their first-person observer-independent ability since their work was mostly for one-off artefacts, architecture and engineering commissions. It took another two hundred years for Monge [12] to invent his descriptive geometry and orthographic projection system to represent and communicate an object precisely and collectively to anyone across the world.

Fast forward until now, Monge never suspected his influence on four industrial revolutions, modernism, postmodernism and today's distributed new product development teams that are increasingly localised. Yet, good drawing on either side of the artistic and engineering divide is again tested by technology. Recent developments are changing the physical and digital base that supports our drawings. Thus, the same drawing can be now either, representation and presentation, a line that models three-dimensionally and simulation of new environments, artefacts and animated characters that evolve in virtual worlds, be 
prototyped easily as material objects because new types of manufacturing, and increasingly, drawing is becoming the end goal of design as well. This new-found complementarity between artistic and engineering drawings poses a challenge for expert practitioners on any side of the divide. This will have a social impact in the community and will also change design practice because a new level of creative competencies and intelligence are needed.

\subsection{Applied Research}

\subsubsection{Observation of students' work (syntaxis level)}

This empirical exercise is on-going to teach, observe and find out students' ability to practically ideate, conceptualise and problem solve. The exercise changes theme each year but keeps similar structure as an organisational group challenge to also assess their improvisatory, embodied and enacted cognitive abilities. Students use drawing's syntactic elements and principles for interpretation, visualisation and decision-making. They are given paper for their visualisations, but they can also use computers and tablets. They are shown professional exemplars and are introduced to Issue-Based Information mapping. Stepping Stones is a game preferred by students. They have to select their team (10-15 in each group) and simulate an emergency situation (e.g. bushfires) that they have to escape from by crossing stepping stones in a river. They must get as many members as possible safely to the other side in short time. Only one person can step on a stone at a time. Stones will sink to the bottom of the river if another person has not stepped on it before the previous member moves forward. The person that does not step on the stone properly is lost to the exercise. After a pause, a second phase follows with two groups trying to cross the river from opposite sides under the same conditions and stepping in the same line of stones.

Repeatedly, students feel out of their comfort zone, but they later like it because they actively experience benefits and shortcomings of their decisions. They feel that group experimentation is longer lasting that their typical individual desk work. They also appreciate not to be told to do artistic or engineering good drawing as they need to resolve a group's action plan, communication and organisation while applying typical syntactic principles (e.g. balance, composition, hierarchy, movement). The contribution of this simple exercise is multifaceted. Succinctly, students are willing to participate and learn when challenged to improvise, embody and enact cognition. Visualisation and syntaxis skills improve with continuous exercises over time. However, results also show that newer generations of students have larger gaps to bridge between their precondition and the professional expectation. It is more difficult for them to translate ideas onto images and further work is required to communicate visually. Many students write short sentences with bullet points instead of drawing their ideas. Others are shy to show their visualisations and say they will present a good drawing done in a computer later (Figure 1).
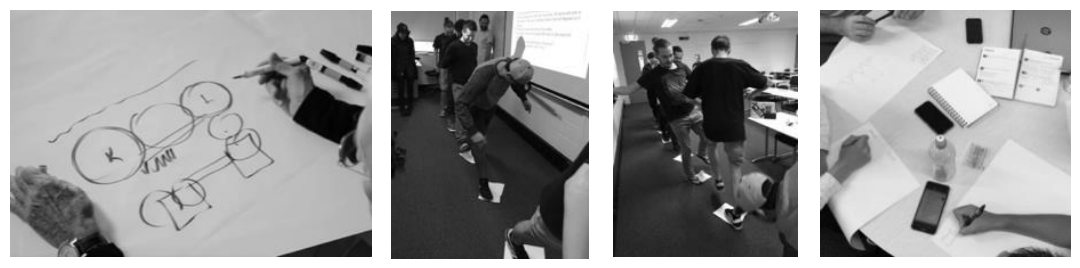

Figure 1. Students' syntaxis exercises with professional visualisation exemplars

\section{First-person experience with traditional techniques (semantics and semiotics levels)}

This exercise intended to experience drawing at semantic and semiotic levels with traditional techniques. The same exercise would repeat within a 3D virtual environment. Designers usually sketch artefacts. However, that type of subject would give an advantage in the virtual environment over the physical techniques. Thus, life drawing was chosen as a subject. Three drawings were planned with intention to force a migration from representation to presentation, and from rational thinking to cognitive embodiment and enaction. The work had to convey a meaningful narrative open to interpretation while still keeping the integrity of the subject drawn. The first drawing would go for three hours to apply Titian's thinking that 'it is not bright colours but good drawing that makes figures beautiful.' This was a sitting pose worked with water colours on an A3 canvas. The second drawing would go for three minutes to capture the expression of a subject in the street. This was a standing up session done with crayons in an A4 drawing book. The third drawing would go for three seconds to capture a moment in a model's life. This was an standing up session drawn with brush and ink on large A0 paper in a studio 
easel. The three hours constrain felt as pressure in the first session. Thus, I had to work rationally to produce a meaningful portrait. Work became playful after a basic structure of the portrait was drawn as support for the watercolour. The three minutes experiment required some other drawings as warming up. Then, I realised that I had to let myself go and stop rationalising the work to help the brain and my hand to capture the subject. The three seconds session was the most involved and intense experience since time constrain simply did not allow to think but only to act by trusting the movement and commitment of the whole body in the process (Figure 2).
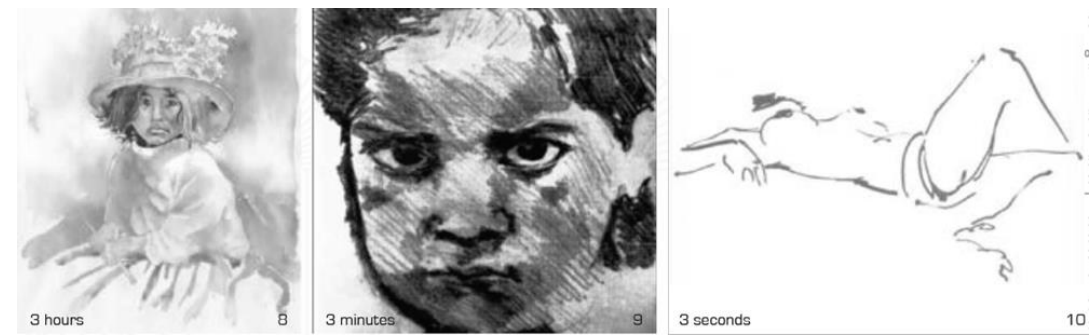

Figure 2. Semantic and semiotic experience with traditional techniques

\subsubsection{First-person experience with 3D VR techniques (semantics and semiotics levels)}

This exercise was about drawing with 3D virtual reality techniques. The plan was to produce several examples with the same timeframe as with the exercises drawn with traditional techniques and compare them. This paper shows a first-time experience with the same skills used as a constant to assess how is that they translate from the physical to the $3 \mathrm{D}$ virtual environment. The examples here belong to a first trial using Google TiltBrush. Other trials with other software are either planned or in progress. There was a steep learning curve and commitment required for this exercise. Once in the virtual environment, the simplicity of one pen or brush that responds to fine motor skills pressure was missing. The means to interface with the 3D virtual environment were two controllers that played on the metaphor of a brush and a palette with a wide range of brushes and tools. Still, the feeling when drawing was of pointing a joystick to the drawing. The three seconds and three minutes sessions were not enough to sketch a life drawing besides checking menus and tools. Most importantly, that time was used to find orientation and settle into the virtual environment. It is very different to draw on a two-dimensional support where the drawer is outside and overseen the progress of the work. In the 3D virtual environment, the drawer is within the three-dimensional space and the subject. However, the three hours session was the most productive and encouraging since the work required full body involvement. Drawing a character larger than human scale in three dimensions was a mix between drawing with a brush, direct 3D CAD development and sculpting. The experience was immersive, similar and as accelerating as the 3 seconds session with traditional techniques. The technical officer warned about the time spent in the virtual environment mostly because of risk of dizziness as it was said that other users fall ill. However, I did not experience major effects and I adjusted quickly outside the experience (Figure 3).
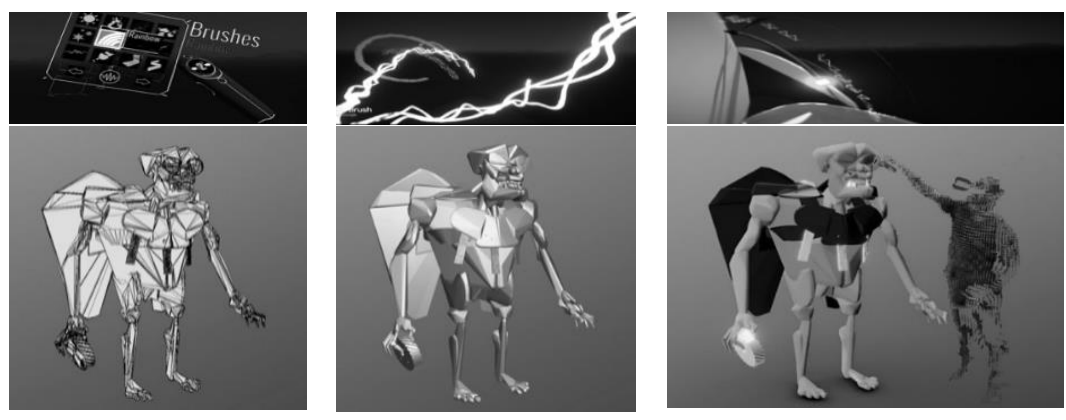

Figure 3. Semantic and semiotic experience with 3D virtual techniques

\section{CONCLUSIONS}

This document was set to recognise and redefine modern design basics before going further. It is said we are in a new Renaissance of society, technology and the profession. Technology is again disrupting society as we enter a new 4.0 Industrial Revolution based on knowledge and innovation-driven economy, and new forms of cyber-physical communications, industries and production. We can learn 
from similar disruptions history with a metamodernist perspective that is restorative of divided relationships between modernism and postmodernism, reason and empiricism, and individual and collective views of the world. Design is essentially link with the act of drawing as its most proximal means of conceptualisation and communication. In the Renaissance, both were named disegno to mean the making of marks and signs. Yet, many practitioners are divided by artistic and technical perspectives with different definition of what is a good drawing. Technology changed design and drawing with the production of paper that displaced animal skin as their support. Then, drawing expanded from image representation to also present novel and unedited ideas that invited dialogue and a process between the drawer and the drawing, the designer and the client, and among their audience. Research, observation and case studies lead to propose that design education needs to progress towards teaching new digital and virtual tools for drawing. This at a time that they are moving from the gaming field into the productivity arena (e.g. iPad, Onshape, LeapMotion, Gravity Sketch, Masterpiece VR). Technology is again changing the format and support of design. Artistic and engineering presentation and representation, individual and collective work are starting to converge visually as easily as the dialogue between the drawer and its drawing. This is a new type of design that students need since their working environment will be distributed and localised. New frameworks based on complementarity, embodied cognition and enactivism will be needed from the emersion of an idea to its development by immersion in a collaborative environment that is physical, digital and virtual. (Figure 4).

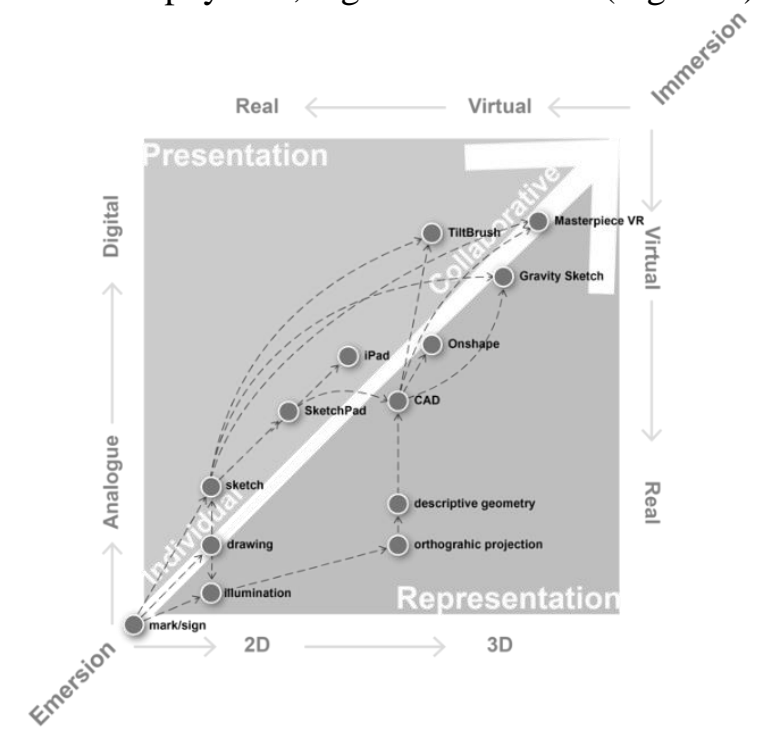

Figure 4. Individual emersion to collaborative immersion framework

\section{REFERENCES}

[1] Carneiro R. Discovering the Treasure of Learning, in Conceptual Evolution and Policy Developments in Lifelong Learning, J. Yang, Editor. 2011, Unesco Institute for Lifelong Learning: Hamburg.

[2] Customer Experience Report from Harvard Business Review Analytic Services. Verizon Enterprise Solutions 2015 2015-11-22 06:41:46.

[3] Fallan K. Design History: Understanding Theory and Method. 2010: Berg.

[4] Sloterdijk P. Bubbles: Spheres Volume I: Microspherology. Translated by Wieland Hoban. 2011.

[5] Sloterdijk P. and Hoban W. Globes : macrospherology. 2014.

[6] Sloterdijk P. and Hoban W. Foams: Spheres - Plural Spherology. 2016: Semiotext(e).

[7] Maturana H. and Varela F. De máquinas y seres vivos. 1998: Universitaria.

[8] Maturana Romecín H. and Varela F.J. El árbol del conocimiento: las bases biológicas del entendimiento humano. 2009: Editorial Universitaria.

[9] Baerveldt C. and Verheggen T.J.C. Enactivism and the experiential reality of culture: Rethinking the epistemological basis of cultural psychology. 1999. 5(2): p. 183-206.

[10] Descartes R.J.P.W. Mediations on First Philosophy. Wherein are Demonstrated the Existence of God and the Distinction of Soul from Body. 1942: p. 61-62.

[11] Kurz O. and Vasari G. Giorgio Vasari's" Libro de'Disegni". 1937: Batsford.

[12] Monge G. Géométrie descriptive. 1811: J. Klostermann fils. 